\title{
All (C57BL/6) mice are not created equal
}

\section{Carly Kiselycznyk* and Andrew Holmes}

Section on Behavioral Science and Genetics, Laboratory of Integrative Neuroscience, National Institute on Alcohol Abuse and Alcoholism, Rockville, MD, USA

${ }^{*}$ Correspondence: kiselycznykc@mail.nih.gov

\section{A commentary on}

Behavioral profiles of three C57BL/6 substrains

by Matsuo, N., Takao, K., Nakanishi, K., Yamasaki, N., Tanda, K., and Miyakawa, T. (2010). Front. Behav. Neurosci. 4:29. doi: 10.3389/fnbeh.2010.00029

Many of the inbred mouse strains employed in behavioral neuroscience exhibit differences in phenotypes ranging from fear regulation to spatial learning to alcohol preference (Belknap et al., 1993; Owen et al., 1997; Bothe et al., 2005; Hefner et al., 2008). The patterns, although not always the degree, of some phenotypic variations are quite stable across time, across studies, and across laboratories (Wahlsten et al., 2006). The good news is that these strain differences offer a tractable and potentially very fruitful means to uncover genetic influences on behavior. The tougher news to swallow relates to many of the extremely powerful mutant mouse tools the field has become heavily invested in. This issue is that the genetic background of these mutants can be a major, and oftentimes unpredictable, determinant of not only the penetrance, but also the direction of behavioral results obtained with, for example, transgenics and targeted gene mutants (Holmes and Hariri, 2003). Those critical of the field might point to this as more evidence of behavioral studies being unpredictable and "soft." On the contrary, in so-called "harder" sciences such as oncology (Krentz et al., 2009) and immunology (Bygrave et al., 2004), the profound influence of genetic background is accepted as being part and parcel of the gene $\times$ gene interactions (epistasis) that underlie complex phenotypes.

How to get a handle on this issue? A good starting point is the careful characterization and comparison of strain phenotypes. Fortunately, much work has been done and discussed in this regard across various behavioral domains. An issue that has not been so well broached in the literature is whether substrains within a single strain also exhibit variation. While we often use shorthand such as "B6" and " 129 " to describe strains, there are in fact multiple substrains of many of the more commonly used inbred strains. The " 129 " family is particularly diverse, with numerous substrains across four separate genetic lineages, and with known phenotypic differences (e.g., Simpson et al., 1997; Bothe et al., 2004; Camp et al., 2009). Diversity within the 129 substrain can become an issue when trying to sort through the "flanking gene" problem that results when genes from a 129 embryonic stem cell donor get passed along with a targeted mutation (Gerlai, 1996). However, there are also multiple substrains of inbred strains more commonly used as genetic backgrounds for backcrossing, including the ever popular C57BL/6 (Figure 1).

Substrains come about for the simple reason that with only minimal romantic encouragement, mice breed. Then their descendents breed and their descendents breed and so on... With time, isolation and a little spontaneous genetic drift, a founder pair can produce a new substrain in as little as three generations (something to bear in mind if you're breeding mice inhouse without "refreshing" the gene pool with an intermittent backcross to a bona fide C57BL/6J - see Crusio et al., 2009). This is more or less what twice happened with C57BL/6. The founder, C57BL/6J, strain traces its origins to Clarence Little's breeding at The Jackson Laboratory in the 1920s (hence the suffix "J" for Jackson). Substrains subsequently arose both by accident and design. For example, C57BL/6N was developed in the middle of the last century at the National Institutes of Health ("N" suffix for $\mathrm{NIH}$ ), and C57BL/6C appears to have been derived from C57BL/6N in the 1970s at the National Cancer Institute (" $C$ " suffix for Cancer). Previous studies have noted differences in genetic polymorphisms between the $\mathrm{C} 57 \mathrm{BL} / 6 \mathrm{~J}$ and $\mathrm{C} 57 \mathrm{BL} / 6 \mathrm{~N}$ substrains (Bothe et al., 2004; Tsang et al., 2005; Zurita et al.,2010) although at least one analysis of common SNP markers found no difference between the C57BL/6N and the C57BL/6C substrains (Mekada et al., 2009).

Given the status of "C57BL/6" as a standard genetic background for behavioral studies with mutants (Crawley et al., 1997), it is important to compare the substrains and describe any differences. Indeed a number of studies demonstrated significant differences between C57BL/6J and C57BL/6N on measures of ethanol preference, conditioned fear, motor coordination, and pain sensitivity (Blum et al., 1982; Bryant et al., 2008). Matsuo et al. (2010) provide a valuable extension of this earlier work by conducting a comprehensive comparison of C57BL/6J, C57BL/6N, and C57BL/6C. They achieved this in two ways: (1) with a conventional analysis of the three substrains on a battery of behavioral tasks, and (2) by taking advantage of a large data inventory the Miyakawa laboratory has accumulated in the course of studying many different mutant lines that were backcrossed onto one of the three C57BL/6 backgrounds (Takao et al., 2007). Because this laboratory employs rigorously controlled test procedures and applies a fairly consistent battery of behavioral tests to phenotype mutants, it was feasible to combine data across studies and conduct a large-scale analysis. Another plus point was that information was available on a comprehensive array of behavioral phenotypes, including measures of neuromuscular strength, pain sensitivity, motor coordination, anxiety-like behavior, locomotion, social interaction, startle responsivity, antidepressant-sensitive behaviors, and spatial working memory.

Corroborating earlier work, the major finding from Matsuo et al.'s comparison was that these three substrains do indeed behave differently. Interestingly, differences were not seen across the board, but were restricted to certain phenotypes, and were especially robust for locomotor activity (relatively high in C57BL/6J), anxietyrelated behaviors (lowest in $\mathrm{C} 57 \mathrm{BL} / 6 \mathrm{~J}$ ) and prepulse inhibition of startle (relatively high in $\mathrm{C} 57 \mathrm{BL} / 6 \mathrm{~N})$. Because all three substrains 


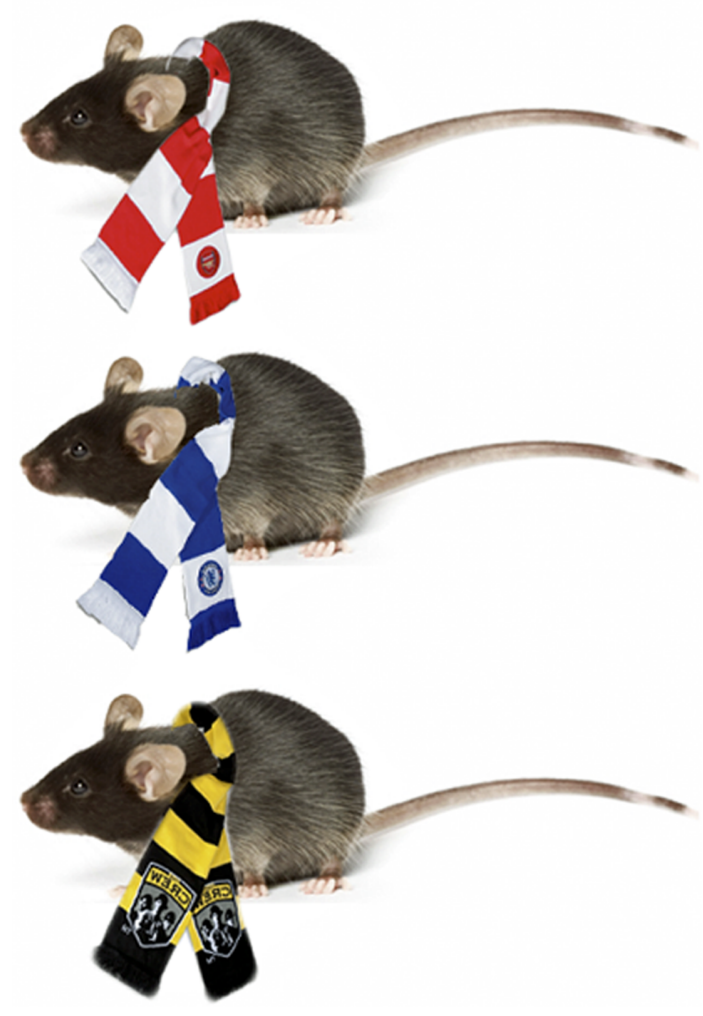

FIGURE 1 |While ostensibly the same, there is growing evidence of significant phenotypic differences between substrains of the C57BL/ 6 inbred mouse.

had the same environment from breeding through testing (including the same testing investigator), the authors could quite confidently attribute the phenotypic differences to underlying genetic variation. This makes the differences between C57BL/6C and $\mathrm{C} 57 \mathrm{BL} / 6 \mathrm{~N}$ all the more striking, given the minimal genetic variation between the two. Moreover, some, but not all, the same differences were replicated in the analysis of the inventoried dataset (which involved between 700 and 2,200 mice, depending on the assay). The discrepancies could be due to early life and test environmental factors, which could not be controlled for in the larger study. They could also be due to genetic influences, as the authors note that at least $80 \%$ were backcrossed more than four generations, many likely fall short of the 10 generations considered a full backcross. Lastly, differences in the order of testing (and inter-test interval) could be another unknown variable contributing to the differences between the results of the direct comparison and inventory analyses (McIlwain et al., 2001).
Nevertheless, Matsuo et al.'s study makes a number of points that all of us working with mice would do well to take on board. Clearly, substrains of C57BL/6 (and other inbred strains) are not all the same. Both investigators and readers of papers need to be as explicit as possible about which substrain is under study. This includes the genetic background of mutants. As Matsuo et al. note, the substrain chosen could determine whether a mutant phenotype can be observed by setting the basal level of behavior against which it is measured. There is also the possibility that subtle genetic variation between the substrains will epistatically interact with the mutation. In fact, if the penetrance of a mutant phenotype was substrain-dependent, this could prove quite a tractable way to identify genetic modifiers, given the degree of variation between two substrains is much less than between two inbred strains. After all, in the real world outside the laboratory it is interactions between genes and between genes and the environment that drives the complexity of behavior (Caspi et al., 2010). More care- ful, thoughtful work like Matsuo et al.'s study will hopefully help us make sense of this reality.

\section{ACKNOWLEDGMENTS}

Thanks to John Crabbe and Valerie Bolivar for valuable comments. The authors are supported by the National Institute on Alcohol Abuse and Alcoholism Intramural Research Program.

\section{REFERENCES}

Belknap, J. K., Crabbe, J. C., and Young, E. R. (1993). Voluntary consumption of ethanol in 15 inbred mouse strains. Psychopharmacology (Berl.) 112, 503-510.

Blum, K., Briggs, A.H., DeLallo, L., Elston, S. F., and Ochoa, R. (1982). Whole brain methionine-enkephalin of ethanol-avoiding and ethanol-preferring c57BL mice. Experientia 38, 1469-1470.

Bothe, G. W., Bolivar, V. J., Vedder, M. J., and Geistfeld, J. G. (2004). Genetic and behavioral differences among five inbred mouse strains commonly used in the production of transgenic and knockout mice. Genes Brain Behav. 3, 149-157.

Bothe, G. W., Bolivar, V. J., Vedder, M. J., and Geistfeld, J. G. (2005). Behavioral differences among fourteen inbred mouse strains commonly used as disease models. Comp. Med. 55, 326-334.

Bryant, C. D., Zhang, N. N., Sokoloff, G., Fanselow, M. S., Ennes, H. S., Palmer, A. A., and McRoberts, J. A. (2008). Behavioral differences among C57BL/6 substrains: implications for transgenic and knockout studies. J. Neurogenet. 22, 315-331.

Bygrave, A. E., Rose, K. L., Cortes-Hernandez, J., Warren, J., Rigby, R. J., Cook, H. T., Walport, M. J., Vyse, T. J., and Botto, M. (2004). Spontaneous autoimmunity in 129 and C57BL/6 mice-implications for autoimmunity described in gene-targeted mice. PLoS Biol. 2, E243. doi: 10.1371/journal.pbio.0020243

Camp, M., Norcross, M., Whittle, N., Feyder, M., D’Hanis, W., Yilmazer-Hanke, D., Singewald, N., and Holmes, A. (2009). Impaired Pavlovian fear extinction is a common phenotype across genetic lineages of the 129 inbred mouse strain. Genes Brain Behav. 8, 744-752.

Caspi, A., Hariri, A. R., Holmes, A., Uher, R., and Moffitt, T. E. (2010). Genetic sensitivity to the environment: the case of the serotonin transporter gene and its implications for studying complex diseases and traits. Am. J. Psychiatry 167, 509-527.

Crawley, J. N., Belknap, J. K., Collins, A., Crabbe, J. C., Frankel, W., Henderson, N., Hitzemann, R. J., Maxson, S. C., Miner, L. L., Silva, A. J., Wehner, J. M., WynshawBoris, A., and Paylor, R. (1997). Behavioral phenotypes of inbred mouse strains: implications and recommendations for molecular studies. Psychopharmacology (Berl.) 132, 107-124.

Crusio, W. E., Goldowitz, D., Holmes, A., and Wolfer, D. (2009). Standards for the publication of mouse mutant studies. Genes Brain Behav. 8, 1-4.

Gerlai, R. (1996). Gene-targeting studies of mammalian behavior: is it the mutation or the background genotype? Trends Neurosci. 19, 177-181.

Hefner, K., Whittle, N., Juhasz, J., Norcross, M., Karlsson, R. M., Saksida, L. M., Bussey, T. J., Singewald, N., and 
Holmes, A. (2008). Impaired fear extinction learning and cortico-amygdala circuit abnormalities in a common genetic mouse strain. J. Neurosci. 28, 8074-8085.

Holmes, A., and Hariri, A. R. (2003). The serotonin transporter gene-linked polymorphism and negative emotionality: placing single gene effects in the context of genetic background and environment. Genes Brain Behav. 2, 332-335.

Krentz, A. D., Murphy, M. W., Kim, S., Cook, M. S., Capel, B., Zhu, R., Matin, A., Sarver, A. L., Parker, K. L., Griswold, M. D., Looijenga, L. H., Bardwell, V. J., and Zarkower, D. (2009). The DM domain protein DMRT1 is a dose-sensitive regulator of fetal germ cell proliferation and pluripotency. Proc. Natl. Acad. Sci. U.S.A. 106, 22323-22328.

Matsuo, N., Takao, K., Nakanishi, K., Yamasaki, N., Tanda, K., and Miyakawa, T. (2010). Behavioral profiles of three C57BL/6 substrains. Front. Behav. Neurosci. 4:29. doi: 10.3389/fnbeh.2010.00029

McIlwain, K. L., Merriweather, M. Y., Yuva-Paylor, L. A., and Paylor, R. (2001). The use of behavioral test batteries: effects of training history. Physiol. Behav. 73, $705-717$.
Mekada,K.,Abe, K., Murakami,A., Nakamura, S., Nakata, H., Moriwaki, K., Obata, Y., and Yoshiki, A. (2009). Genetic differences among C57BL/6 substrains. Exp Anim. 58, 141-149.

Owen, E. H., Logue, S. F., Rasmussen, D. L., and Wehner, J. M. (1997).Assessment of learning by the Morris water task and fear conditioning in inbred mouse strains and F1 hybrids: implications of genetic background for single gene mutations and quantitative trait loci analyses. Neuroscience 80, 1087-1099.

Simpson, E. M., Linder, C. C., Sargent, E. E., Davisson, M T., Mobraaten, L. E., and Sharp, J. J. (1997). Genetic variation among 129 substrains and its importance for targeted mutagenesis in mice. Nat. Genet. 16 19-27.

Takao, K., Yamasaki, N., and Miyakawa, T. (2007). Impact of brain-behavior phenotypying of geneticallyengineered mice on research of neuropsychiatric disorders. Neurosci. Res. 58, 124-132.

Tsang, S., Sun, Z., Luke, B., Stewart, C., Lum, N., Gregory, M., Wu, X., Subleski, M., Jenkins, N. A., Copeland, N. G., and Munroe, D. J. (2005). A comprehensive SNP-based genetic analysis of inbred mouse strains. Mamm. Genome 16, 476-480.
Wahlsten, D., Bachmanov, A., Finn, D. A., and Crabbe, J. C. (2006). Stability of inbred mouse strain differences in behavior and brain size between laboratories and across decades. Proc. Natl. Acad. Sci. U.S.A. 103 , 16364-16369.

Zurita, E., Chagoyen, M., Cantero, M., Alonso, R., Gonzalez-Neira, A., Lopez-Jimenez, A., LopezMoreno, J. A., Landel, C. P., Benitez, J., Pazos, F. and Montoliu, L. (2010). Genetic polymorphisms among C57BL/6 mouse inbred strains. Transgenic Res. doi: 10.1007/s11248-010-9403-8. [Epub ahead of print].

Received: 13 January 2011; accepted: 14 January 2011; published online: 23 February 2011.

Citation: Kiselycznyk Cand Holmes A (2011) All (C57BL/6) mice are not created equal. Front. Neurosci. 5:10. doi: 10.3389/fnins.2011.00010

Copyright (c) 2011 Kiselycznyk and Holmes. This is an open-access article subject to an exclusive license agreement between the authors and Frontiers Media SA, which permits unrestricted use, distribution, and reproduction in any medium, provided the original authors and source are credited. 